\title{
Improved Staff Procedure Skills Lead to Improved Management Skills: An Observational Study in an Educational Setting
}

\author{
Anders Rüter, MD, PhD; Tore Vikstrom, MD, PhD
}

Faculty of Health Science, Department of Clinical and Experimental Medicine, Centre for Teaching and Research in Disaster

Medicine and Traumatology, Sweden

\author{
Correspondence: \\ Anders Rüter \\ Centre for Teaching and Research in \\ Disaster Medicine and Traumatology \\ University Hospital \\ S-581 85 Linoping \\ Sweden \\ E-mail: anders.ruter@lio.se
}

Keywords: command and control; disaster medicine; education; Emerge Train System; incidents; management skills; performance indicators; simulation exercise; staff procedure skills

\section{Abbreviations: \\ None.}

\section{Received: 01 July 2008}

Accepted: 04 August 2008

Revised: 16 October 2008

Web publication:

\begin{abstract}
Introduction: Good staff procedure skills in a management group during incidents and disasters are believed to be a prerequisite for good management of the situation. However, this has not been demonstrated scientifically. Templates for evaluation results from performance indicators during simulation exercises have previously been tested. The aim of this study was to demonstrate the possibility that these indicators can be used as a tool for studying the relationship between good management skills and good staff procedure skills.

Hypothesis: Good and structured work (staff procedure skills) in a hospital management group during simulation exercises in disaster medicine is related to good and timely decisions (good management skills).

Methods: Results from 29 consecutive simulation exercises in which staff procedure skills and management skills were evaluated using quantitative measurements were included. The statistical analysis method used was simple linear regression with staff procedure skills as the response variable and management skills as the predictor variable.

Results: An overall significant relationship was identified between staff procedure skills and management skills $(p \leq 0.05)$.

Conclusions: This study suggests that there is a relationship between staff procedure skills and management skills in the educational setting used. Future studies are needed to demonstrate if this also can be observed during real incidents.
\end{abstract}

Ruter A, Vikstrom T: Improved staff procedure skills lead to improved management skills: An observational study in an educational setting. Prehosp Disaster Med 2009;24(5):376-379.

\section{Introduction}

A prerequisite for good performance in a management group is that the work is performed in a structured way. In emergency management, as well as in military training, it often is mandatory for persons in decision-making positions to participate in training on how to work in a staff, and training in staff procedure skills. ${ }^{1-3}$ It is believed that good and systematic procedures in staff work will lead to better decisions. However, the relationship between management skills and staff procedure skills has not, to our knowledge, been demonstrated in a scientific way. Management skills are defined as the ability to make correct and timely decisions. Staff procedure skills mean the ability for a staff to work in a structural and instrumental way.

In order to make it possible to study relationships using quantitative measurements, there must be educational models in which results can be expressed in numbers. There are models using self-assessment as an indicator of the quality of performance, but in order to make results more objective, there is a need for evaluation of performance based on observations by a trained instructor. ${ }^{4}$ An educational model using measurable performance indicators has been developed in which the results from training in disaster management at different levels can be expressed in numbers. The staff procedure skills were evaluated using the same technique. ${ }^{5,6}$ The aim of this study was to demon- 


\begin{tabular}{|l|c|}
\hline \multicolumn{1}{|c|}{ Performance Indicator } & $\begin{array}{c}\text { Standards } \\
\text { (minutes) }\end{array}$ \\
\hline 1. Decide on level of preparedness & 3 \\
\hline 2. Formulate initial guidelines for response & 15 \\
\hline 3. First information to the media & 15 \\
\hline $\begin{array}{c}\text { 4. Give information about own resources to } \\
\text { strategic management }\end{array}$ & 25 \\
\hline $\begin{array}{c}\text { 5. Ensuring medical officers appointed at } \\
\text { [?] }\end{array}$ & 30 \\
\hline 6. Emergency and operation & 45 \\
\hline 7. Estimate need of ICU beds & 60 \\
\hline 8. First information to own staff & 120 \\
\hline 9. Estimate limitations of own capacity & 120 \\
\hline 10. Evaluate impact on daily patients & 180 \\
\hline $\begin{array}{l}\text { 11. Information plan for patients with postponed } \\
\text { operations and visits }\end{array}$ & Rüter @ 2009 Prehospital and Disaster Medicine \\
\hline
\end{tabular}

Table 1-Performance indicators and standard (minutes) for each indicator for management skills for hospital management groups during disaster medicine training. The possible result of each indicator is 0,1 , or 2 . Total possible score is $11 \times 2=22$.

strate the use of measurable performance indicators as a tool for studying the relationships between staff procedure skills and management skills of hospital management groups during disaster medicine training.

\section{Methods}

Results from 29 consecutive training sessions (2004-2007) for hospital management groups during simulated major incidents and disasters were included. The training took place either at a national training center $(\mathrm{n}=25)$ or in hospital management rooms designed for real incidents $(n=4)$. The management rooms at the training center are equipped and sized similar to real management rooms, the two different types of premises were, therefore, considered as equal. The educational system used for training was Emergo Train System. ${ }^{7}$ Using this educational system, incidents and disasters can be simulated using symbols on magnetic whiteboards; the core content consists of a victim bank. The scenarios were: a bus-crash with a truck loaded with ammonia; fire and collapse of a football stand; or a train crash. Prior to the training, all participants had been presented lectures both on management skills as well as staff procedure skills. ${ }^{8}$ There were $4-6$ participants in each management group. All groups were monitored by a trained instructor in disaster medicine using close circuit television (CCTV). All results were documented using templates developed for management skills and staff procedure skills. ${ }^{5}$

Results were evaluated according to previously developed templates of performance indicators (Tables 1 and 2). These templates also are used in other trainings as well as
1. Assigning functions to all staff-members directly upon arrival
2. Placement in room according to function in staff
3. Designated telephone numbers
4. Introduction of newly arrived staff member, Maximum = 1 minute
5. Utilization of available equipment ${ }^{*}$
6. Maximum 8 minutes for "staff briefing"
7. Content of "staff briefing"? ${ }^{\dagger}$
8. Telephone discipline during staff briefing
9. Drawing and content of "staff schedule"
10. Summary after session, orally
11. Summary after session, written

Rüter @ 2009 Prehospital and Disaster Medicine

Table 2-Performance indicators for staff procedure

skills for hospital management groups during disaster medicine training. The possible result of each indicator is 0,1 , or 2 .

Total possible score is $11 \times 2=22$

"Equipment available: Whiteboard, flipchart, fax, computer ${ }^{\dagger}$ Reports from all functions, summarizing, assigning new tasks, time for next briefing

\begin{tabular}{|l|c|c|}
\hline & $\begin{array}{c}\text { Training } \\
\text { Center }\end{array}$ & $\begin{array}{c}\text { Real Management } \\
\text { Rooms }\end{array}$ \\
\hline $\mathrm{n}$ & 25 & 4 \\
\hline Management Score & 13.8 & 13.8 \\
\hline Staff Procedure Skills & 17.4 & 14.7 \\
\hline
\end{tabular}

Table 3-The average score for management groups during training in management rooms at training center or management rooms used during real incidents

during real incidents. The different management groups were given a score of 0,1 , or 2 for each of the 11 performance indicators. Thereby, the highest possible score was 22 points for management skills and 22 points for staff procedure skills. If there were any questions regarding performance or results, these were discussed with the person responsible for the training and research (AR).

The statistical analysis method used was simple linear regression with staff procedure skills as the response variable and management skills as the predictor variable.

\section{Results}

There was no difference in the average score for management skills between training conducted at a training center $(\mathrm{n}=25)$ compared with the training at the hospital management rooms designed for real incidents $(n=4)$ (Table 3 ). The results of the staff procedure skills were slightly better at the training centre. The highest score given for staff procedure skills was 20.75 points, the lowest was 13.0 points (Table 4). The highest score for management skills was 21 points and the lowest was 6 points (Table 4). When comparing management skills to staff procedure skills, an overall significant relation between both of the variables was identified ( $\mathrm{p} \leq 0.05$; Figure 1$)$.

\section{Discussion}

Although teaching of staff procedure skills, how to manage command and control during an incident, is an issue that has been taught for many years in the military setting and in the rescue service, this training is quite new for hospital 


\begin{tabular}{|c|c|c|}
\hline $\begin{array}{c}\text { Hospital } \\
\text { Management }\end{array}$ & $\begin{array}{c}\text { Staff Procedure } \\
\text { Skills }\end{array}$ & Management skills \\
\hline Number on Group & Score & Score \\
\hline $1 \mathrm{a}$ & 17.0 & 16 \\
\hline $1 b$ & 20.0 & 21 \\
\hline $1 c$ & 17.0 & 15 \\
\hline $2 a$ & 19.0 & 16 \\
\hline $2 b$ & 18.5 & 21 \\
\hline $3 a$ & 19.25 & 13 \\
\hline $3 b$ & 21.25 & 17 \\
\hline $3 c$ & 16.0 & 10 \\
\hline $4 a$ & 19.5 & 18 \\
\hline $4 b$ & 20.75 & 14 \\
\hline $4 c$ & 20.2 & 15 \\
\hline $4 d$ & 20.35 & 13 \\
\hline $5 a$ & 15.0 & 14 \\
\hline $6 a$ & 14.0 & 13 \\
\hline $6 b$ & 16.0 & 17 \\
\hline $6 c$ & 15.0 & 15 \\
\hline $7 a$ & 18.0 & 18 \\
\hline $7 b$ & 17.25 & 8 \\
\hline $8 a$ & 15.0 & 11 \\
\hline $8 b$ & 13.25 & 8 \\
\hline $8 c$ & 16.75 & 6 \\
\hline $8 d$ & 13.25 & 6 \\
\hline $8 e$ & 13.0 & 12 \\
\hline $8 f$ & 17.25 & 13 \\
\hline $9 a$ & 16.0 & 16 \\
\hline $9 b$ & 14.75 & 14 \\
\hline $9 c$ & 13.0 & 11 \\
\hline $10 a$ & 21.0 & 14 \\
\hline $10 \mathrm{~b}$ & 17.5 & 16 \\
\hline
\end{tabular}

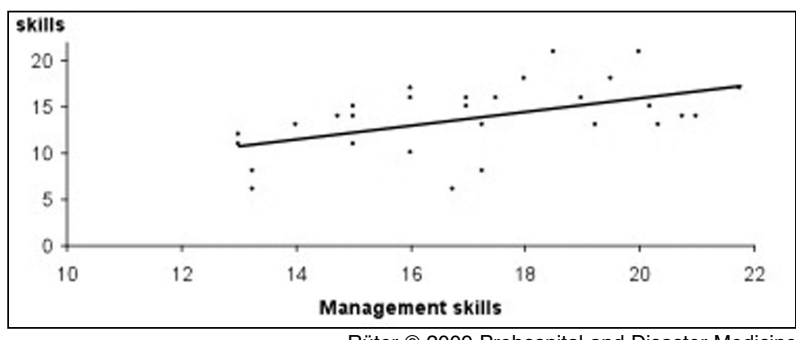

Rüter (c) 2009 Prehospital and Disaster Medicine

Figure 1-There is a linear relationship between staff procedure skills and management skills. $(p \leq 0.05$ using Pearson correlation)

staff. However, experiences from staff work, demonstrated in educational settings where the members, in advance, have had the possibility to work together, has demonstrated the need for more education and training. ${ }^{5,9}$ During optimal conditions, persons that are trained together should be the same persons that will work together during an incident, but this is difficult to achieve in the healthcare system. One reason is the necessity of making decisions at a very early phase during the incident. This leads to the necessity of basing the initial management groups on immediately available doctors and nurses on call.

To optimize the situation for these early decision-makers, the work must be very structured and well-organized. It previously has been demonstrated that staff procedure skills can be measured in a fairly objective way. ${ }^{5,6}$ Studies also have demonstrated that the management skills on different levels can be measured and results can be analyzed using quantitative methods. ${ }^{10,11}$

In this study, different management groups, all simulating hospital management during major incidents were studied. Of course this is an artificial setting and whether these results are valid during real incidents is yet to be studied. In order for this to happen, more sophisticated information retrieval systems than paper and pen may be needed; otherwise, there is the possibility that important information may be lost. ${ }^{12}$ In this study setting, the management groups are observed by trained observers using closed-circuit television (CCTV), or if the exercise was performed in real management rooms, by a trained person positioned in the room during the exercise. This model has been used for a number of years at this center and several incident managers from the different county councils have been trained in this way. The simulation technique that also allows results to be presented in relationship to patient outcome also has been demonstrated previously. ${ }^{13}$

The two different sets of performance indicators that were used reflect somewhat different types of problemsolving skills. The indicators used for evaluating management skills and most, but not all, of the indicators for staff procedure skills (number 1,7,8,10, and 11) are related to the analytical skills of the groups, or at least one individual of the group. The other skills are more of a mechanical measurement type. ${ }^{14,15}$ However, the indicators have been developed as a consequence of a national development project, and have not been considered as being too difficult or

high-level to achieve a good results.
Table 4-The score of 29 hospital management groups in staff procedure skills and management skills demonstrated during training in disaster management. The management groups that were trained during the same session are indicated by having the same number. 
There were no differences with regard to the management groups trained at the centre $(\mathrm{n}=25)$ compared to the ones trained at their own facilities $(n=4)$ (Table 1$)$; however, because of the small number of groups trained in real incident rooms, caution must be taken with this conclusion.

When the results of staff procedure skills were compared to management, a significant correlation was found between these two variables (Figure 1). This suggests that, at least in this model, there may be a need for hospital managers during disasters and major incidents to be trained in good staff work. This correlation also might reflect that the persons and groups in this study possess analytical skills, and that these skills are important in the management of disaster and major incidents. ${ }^{14}$ If more results lead to the same conclusion, this should have an impact on what training should be performed when preparing hospital management groups. Disaster management not only should include training in making correct and timely decisions, but also skills in how to work in a structural way. Given the results from previous studies, this training should be performed repeatedly. ${ }^{5}$ Validation of both the model and the indicators must be done. However, this important first step will provide information on an area of training that may require more attention in the future.

Another issue that must be addressed is whether these results can be compared to results from other types of train- ing, e.g., computer simulation. When comparable models have been developed, results may give a clue to what is the most effective both from a learning perspective and an economic perspective. Perhaps, even more important is the question of whether the knowledge learned in different training programs will be retained. How frequent is the training needed in order to be confident that the results will be the same in real situations? The skills tested in this study are of procedural type and it is well known that these skills demand more practice and are more easily forgotten than are psychomotor skills. ${ }^{16}$ Repeated studies may be needed; however, this probably would require training and evaluation at a local level and not at a national training center in order to ensure that the groups and/or persons are tested. The most important issue of whether or not these results have an impact on patient outcome is not addressed in this paper. Previous studies indicate that this can be possible in educational models; however, during real incidents, more variables with clinical data must be linked to the results of skills in management and staff procedures.

\section{Conclusions}

This study suggests that a relationship exists between staff procedure skills and management skills during training in hospital disaster management. More studies are needed to determine if this relationship also can be demonstrated during real incidents and/or disasters.
References

1. Swedish Rescue Services Agency: Available at http://www.raddningsverket.se/upload/utbildningar/skövde/pdf_sv/produktblad/ledningstabtjänst_gr und.pdf. Accessed 04 September 2006.

2. Swedish Defence Research Agency: Available at http://www.foi.se/FOI/tempaltes/page_404.aspx. Accessed 04 September 2006.

3. Swedish National Defence College. Available at http://www.fhs.mil.se/utbkatalog. Accessed 04 September 2006.

4. Hsu E, Jenckes M, Catlett C, et al: Effectiveness of hospital staff mass-casualty incident training methods: A systematic literature review. Prehosp Disaster Med 2004;19:191-199.

5. Rüter A, Örtenwall P, Vikström T: Staff procedure skills in management groups during exercises in disaster medicine. Prehosp Disaster Med 2007;22(5):318-321.

6. Rüter A, Nilsson H, Vikström T: Performance indicators as quality control for testing and evaluating hospital management groups: A pilot study. Prehosp Disaster Med 2006;21(6):423-426.

7. Emergotrain. Available at http://www.emergotrain.com Accessed 28 April 2008.

8. Rüter A, Nilsson H, Vikström T: Medical Command and Control at Incidents and Disasters: From the Scene of Incident to the Hospital Ward. Lund, Sweden: Studentlitteratur 2006, pp 1-96.
9. Auf der Heide E: Principles of Hospital Disaster Planning. In: Hogan D, Burnstein J (eds), Disaster Medicine. Philadelphia: Lippincott and Wilkins, 2002, pp 57-89.

10. Rüter A, Örtenwall P, Vikström T: Performance indicators for prehospital command and control in training of medical first responders. International Journal of Disaster Medicine 2004;2(3):89-92.

11. Adani B, Goldberg A, Laor D, et al: Editorial comments-Staff procedure skills in management groups during exercises in disaster medicine. Prehosp Disaster Med 2007;22(4):322-324.

12. Rüter A: Disaster medicine-Performance indicators, information support and documentation. Linköping University Medical Dissertation No. 972, November 2006.

13. Nilsson H, Rüter A: Management of resources at disasters and major incidents in relation to patient outcome-A pilot study of an educational model. Eur J Emerg Med 2008;15:162-165.

14. National Workforce Center for Emerging Technologies: College Curriculum. Information Technology Core Curriculum. Available at http://www.nwcet.org/downloads/SoftSkillsITCoreCurr.pdf Accessed 16 October 2008.

15. Wikipedia. Available at http://en.wikipedia.org/wiki/Analytical_skills. Accessed 16 October 2008. [AU please provide source other than Wikipedia]

16. Ginzburg S, Dar-el EM: Skill retention and relearning-A proposed cyclical model. J Workplace Learning 2000;12(8):327-332. 